\title{
Care-givers' Reflections on an Ethics Education Immersive Simulation Care Experience: A Series of Epiphanous Events
}

Authors: Ann Gallagher, Matthew Peacock, Magda Zasada, Trees Coucke, Anna Cox \& Nele Janssens

\begin{abstract}
There has been little previous scholarship regarding the aims, options and impact of ethics education on residential care-givers. This manuscript details findings from a pragmatic cluster trial evaluating the impact of three different approaches to ethics education. The focus of the article is on one of the interventions, an immersive simulation experience. The simulation experience required residential care-givers' to assume the profile of elderly care-recipients for a 24 hour period. The care-givers were student nurses. The project was reviewed favourably by a university ethics committee and participants provided informed consent. Data from 6 post-simulation experience focus groups were analysed thematically and three themes were identified: the experience of vulnerability; dignity in care; and the organisation of care. Findings suggest that the immersive simulation experience had a powerful immediate impact as participants described epiphanous insights relating to their care experiences. It is suggested that reflecting on and recording epiphanous events has the potential to sustain ethical care practices. Further research is required to evaluate the impact of different ethics education interventions in different cultural contexts. Exploration is also required regarding the meaning and significance of care epiphanies, those 'most delicate and evanescent of moments', for the sustainability of ethical care.
\end{abstract}

\section{Keywords}

Immersive simulation, ethics education, care-givers, care-recipients, RIPE project, care epiphanies 


\section{Introduction}

In 2011 over a quarter of a million $(290,000)$ older people were known to live in care homes In England and Wales (Office for National Statistics, 2014). Of 1.6 million social care-givers, $40 \%$ work in residential care (Skills for Care 2013). Workers who deliver care to older people encounter a range of ethical issues (Preshaw, Brazil \& McLaughlin, 2016; Suhonen, Stolt, Launis \& Leino-Kilpi, 2010). Reports of care deficits in residential care for older people have resulted in concern about standards of care and in educational initiatives to promote ethics in care. The evidence base for ethics education for residential care-givers is undeveloped and the impact of ethics education on care-givers' ethical competence is currently unknown. The RIPE (Researching Interventions to Promote Ethics in social care) project is a pragmatic cluster trial which sets out to remedy this research gap by exploring the effectiveness of three ethics educational interventions for care-givers working in residential care homes for older people (Gallagher \& Cox, 2015). This paper reports elements of findings from a thematic analysis of six focus groups with care-recipients or 'simulants' and student nurses (care-givers) who participated in the immersive simulation intervention. The findings focused on illustrations of the potential of an immersive simulation experience to provoke epiphanous experiences in relation to the three data themes: the experience of vulnerability; dignity in care; and the organisation of care.

\section{Background}

There has been a good deal of international research attention to ethical aspects of the care of older people. Suhonen et al. (2010) write that whilst 'ethical issues in health care receive much publicity, attention is rarely given to the non-dramatic, everyday ethics [..]' . A recent literature review, relating specifically to the ethical issues experienced by care-givers in nursing homes, highlighted four themes: clashes of ethical principles; communication issues; scarcity of resources; and provision of quality of care (Preshaw et al., 2016). In the UK, discussion of ethical aspects of residential care for older people has focused on human rights (Northern Ireland Human Rights Commission, 2012), on dignity and compassion in care and, more broadly, on quality of life in care homes (Help the Aged, 2007). There has been recognition that there is a need for constructive responses to care deficits in the National Health Service (Francis, 2013) and scandals in care homes (BBC, 2014, 2015; MacFarlane, 2013; Sawer, 2014). Organisations such as the Royal College of Nursing, Age UK and the Commission on Improving Dignity in Care have conducted research and developed ethics educational resources.

Ethics education is now a mandatory part of the curriculum for student health professionals in the UK. In general terms, it aims to develop ethical competence by promoting ethical perception and sensitivity, by enabling reflection on personal and professional values, by raising awareness of ethical aspects of care practice, by building confidence in ethical decision-making and by empowering practitioners with the skills and knowledge necessary to act ethically (Gallagher, 2006). In 2003, McFarlane and McLean found that $80 \%$ of care home workers had no formal qualifications or training and that efforts to increase the uptake of training had limited effects. In 2016, the picture looks quite different, with the implementation of the NVQ awards, and most recently the Care Certificate. A number of the standards that 
comprise the Care Certificate relate specifically to ethics in care, for example, duty of care, person-centred care, equality and diversity and dignity and privacy (Skills for Care, 2016).

It is not yet known which is the most effective approach to promoting ethics in care, however, there have been some comparisons in health professional education of approaches such as face to face teaching, reflective groups, online learning or a blended approach (Trobec \& Starcic, 2015). There has also been a good deal of recent interest in the potential of simulation to promote clinical skills generally (Carroll \& Messenger, 2008). Simulation has been described as 'a complex social endeavour' whereby humans interact with each other in an 'as-if' situation (Dieckmann, Gaba \& Rall 2007). It can take many forms and utilise a range of technologies, artefacts and environments such as computers, mannequins and care or clinical areas to comprise a simulated 'reality'. Uwe Laucken (1999) details three ways or modes of thinking about reality in relation to simulation: physical; semantical; and phenomenal. The former relates to the physical characteristics of equipment and the environment which can be described and, in some instances, measured. The second way of thinking is semantical and relates to theory and concepts which may be presented variously, for example, in describing the philosophical underpinning of a simulation experience. The third way of thinking about reality, the phenomenal mode, is described as including 'emotions, beliefs and self-aware cognitive states of rational thought that people directly experience while in a situation' (Dieckmann et al 2007 p.185).

Regarding ethics in care specifically, the sTimul programme (Vanlaere, Coucke \& Gastmans, 2010) originated in Flanders in 2008 and pioneered the concept of the 'care-ethics lab'. This is a simulated care home environment where participants (who are care-givers) assume the roles of care-recipients over the course of two days and one night. They then take part in ethical reflection sessions based on their experience. A study with participants in the Flanders sTimul programme focused on the development of empathy and found overall that 'all participants underwent at least one care experience that really affected them' (Vanlaere, Timmermann, Stevens \& Gastmans, 2012, p. 73). The researchers went on to say that: 'It is particularly the experience of physical and mental misery that made many participants stop and think. They called these experiences eye-openers, which led to new insights into their view on care' (p. 75).

Reference to 'eye openers' suggests what we will be referring to as 'epiphanous events', however, we found no previous scholarship that reported the experience of epiphanies in care explicitly. Some scholarship examines 'aha moments' (Willis, 2007), 'aha experiences' (Copley, 2001) in education and describes new insights regarding recognition of the importance of the 'little things' in care (Williams, Kinnear and Victor, 2015). Dictionary definitions assert that the word 'epiphany' comes from the Greek epiphaneia which means 'manifestation, striking appearance' and refers to an experience of sudden realisations leading to discoveries or insights that may be religious, philosophical or scientific. The phenomenon of 'epiphany' also has references in Christianity (BBC, 2011), philosophy and literature (Chappell, undated; Joyce, 1992). In the introduction to James Joyce's Dubliners (Joyce, 1992, p. xxxiv), for example, 'epiphany' is described as: 
or in a memorable phrase of the mind itself. He believed it was for the man of letters to record these epiphanies with extreme care, seeing that they are the most delicate and evanescent of moments.

Vanlaere et al. (2010, p. 335) argue that there is a need for further research to evaluate the impact of the simulation experience and to explore 'the connection between experience-oriented learning and ethical reflection'. The RIPE study is one such piece of research, evaluating the sTimul approach (Vanlaere et al., 2010) in relation to two other ethics education interventions: face to face ethics teaching and reflective groups discussing ethical aspects of care situations.

\section{Methodology}

In the RIPE Project the three interventions and a control group comprise the four arms of a pragmatic trial with outcome measures gauging moral sensitivity, ethical leadership, moral stress and empathy (Gallagher \& Cox, 2015). The simulation intervention follows closely the model established by Vanlaere et al. (2010). This paper describes qualitative data from focus groups which followed the immersive simulation experience in which residential care-givers spent 24 hours in the University of Surrey's simulation suite.

The university simulation suite was adapted so it was similar to a care home environment with dining room, lounge, bathrooms and bedrooms.. Simulation participants - care-givers who would assume the profile of care-recipients (simulants) and second and third year student nurses who would be their care-givers - arrived at the simulation suite at 12 midday and had lunch together. All participants were advised not to discuss their actual care roles or experience at this point. After lunch, simulants were given time to assume the profile of an older person receiving residential care. Props were provided to simulate sensory and physical deficits, for example, ear plugs, walking aids, wheelchairs and incontinence aids. They were then brought together with student nurses where they shared their simulant profile (See Supporting Materials $1 \& 2$ for simulation overview and for profile summary template). The simulation experience ran from $2 \mathrm{pm}$ to $7 \mathrm{pm}$ and from $8 \mathrm{pm}$ to $12 \mathrm{md}$ on Day 1 and from 6am to $1 \mathrm{pm}$ on Day 2. Care was not delivered overnight. The one hour break on Day 1 was for discussion with simulation facilitators and provided the opportunity for simulant (care-recipients) and student nurse (care-givers) groups to separately give feedback to a facilitator which was then passed to the relevant group. If, for example, students reported that a simulant appeared to be having difficulty remaining in the profile of a care-recipient, the latter would reflect on this and be more aware of behaviours.

Once a favourable ethical opinion was obtained from the University of Surrey Ethics Committee recruitment of care homes began. Participant information sheets were distributed to potential participants and written informed consent obtained before commencing the simulation. Participation was voluntary and participants were assured that they could decline or withdraw from any activity at any time. Simulants and student nurses were made aware that facilitators (at least one a Registered Nurse) and a researcher were available at during the simulation and they could seek advice or support at any time. The Day 1 feedback discussion with each group and regular observations by the simulation facilitator ensured that participants remained safe. Careful debriefing is an important feature of simulation experiences and provides the opportunity to discuss any outstanding issues that may result in anxiety or distress 
for participants.(Levett-Jones \& Lapkin, 2014).

\section{Focus groups}

This paper reports findings from six focus groups with care-givers from residential settings participating in the project (simulants) and student nurses, which were carried out directly after the simulation came to an end. Participants in each of the focus groups were as follows:

\begin{tabular}{|l|l|l|}
\hline $\begin{array}{l}\text { Post-simulation focus } \\
\text { group (FG) }\end{array}$ & Care-givers/simulants & Student nurses \\
\hline $\mathbf{1}$ & $\mathbf{6}$ & $\mathbf{3}$ \\
\hline 2 & 5 & 2 \\
\hline 3 & 4 & 4 \\
\hline 4 & 4 & 2 \\
\hline 5 & 6 & 3 \\
\hline 6 & 5 & 4 \\
\hline
\end{tabular}

Table 1 - Focus Group Participants

Bringing together the simulants (simulation care-recipients) and the student nurses (simulation care-givers) in a focus group to reflect on their experience provided participants with the opportunity to explore their common experiences in a more natural environment than would be the case if this was explored through individual interviews. A safe space was provided to talk immediately about their experiences at the end of six simulation weekends, therefore, their responses were still fresh.

\section{Data analysis}

Data from the focus groups were digitally audio-recorded, transcribed and qualitatively analysed using thematic analysis (Braun \& Clarke, 2006). Thematic analysis is a meticulous inductive method which uses the data as the basis for the systematic generation and ongoing refinement of categories at different levels of abstraction. This facilitates both a rigorous methodological process and the flexibility to validly reflect the patterns found in participant's accounts whilst maintaining a reflexive awareness of the researchers' own biases and preconceptions. Close reading of the data resulted in the generation of initial themes which were then refined, pruned and amalgamated to produce overarching themes at higher levels of abstraction. The analysis was validated by two other members of the research team, resulting in the thematic structure presented below.

\section{Findings}

The thematic analysis resulted in three main themes, with sub-themes, which captured the essence of the variability found in the data. They validly describe the experience of the participants and their epiphanous nature. The themes and subthemes are presented in the table below and elaborated on in the text that follows:

\section{Themes}

\section{Sub-themes}




\begin{tabular}{|l|l|}
\hline The experience of vulnerability & $\begin{array}{l}\text { - Dependency } \\
\text { - Fear of abandonment } \\
\text { - Lack of control }\end{array}$ \\
\hline Dignity in care & $\begin{array}{l}\text { - Discretion } \\
\text { - Autonomy }\end{array}$ \\
\hline The organisation of care & $\begin{array}{l}\text { - Communication } \\
\text { - The little things make a } \\
\text { - difference }\end{array}$ \\
\hline
\end{tabular}

\section{Table 2 - Themes and sub-themes}

\section{Theme 1 - The experience of vulnerability}

Vulnerability was a concept referred to by simulants (simulation care-recipients) and student nurses in the post-simulation focus groups. The simulants particularly referred to feelings of dependency, to fear of abandonment and to experiencing a lack of control.

\section{Dependency}

Much of the vulnerability referred to by simulants related to their dependence on others to fulfil basic physical needs. Whilst otherwise healthy and independent, simulation care-recipients might be expected to experience some vulnerability in this situation. The intensity of this reaction was nonetheless striking. Care-recipients were quite shaken when everyday tasks they took for granted suddenly required them to enlist the assistance of others, for example in relation to washing and feeding:

The most vulnerable time for me was during the bed bath (laughs) [FG2].

I felt very vulnerable when I was being fed because if they didn't feed me then I was getting no food, no nothing [FG6].

The fact that such experiences resulted in an insight that may be described as epiphanous is evident also in the next data extract:

It's made me realise how much the residents need our help, if that makes sense.

But obviously I know they needed it before, but not really to that extent [FG6].

Fear of abandonment

In addition to the vulnerability that arose from dependency, simulants feared that help might not come in time and they might have no means by which to call for help: 
the character I portrayed... she didn't have access to her call bell, she would actually end up feeling very vulnerable because she's not the sort that would shout out or alert anybody in any other way that she needed help. So to actually be isolated with no way of raising the attention of your carers - that would make you feel very very vulnerable [FG2].

The fear of abandonment expressed was especially prominent in situations when timesensitive needs required the assistance of care-givers who were not currently in the room:

So I felt a bit vulnerable then [on the toilet] cos I thought "Well shall I just check that they're there? Oh no, I can't walk. So l'll just sit here and call out and hope that they're there." But it's strange, just in that second going "Do you think they're gone?" [FG6].

This suggests a newfound appreciation that even if a care-giver is in the next room or outside the toilet door, to the recipient they have simply 'disappeared' or 'gone' and for all they know may be too far away to help. The experience of having to entrust one's care to others helped recipients to better understand the feelings of those they care for and their families:

This is how it feels you know when someone hands over their loved ones to you - it's how you bond to that person, to the family. Because they need to trust you [FG1].

This observation, something of an epiphany to the simulant in question, illustrates a different sense in which fear of abandonment plays a role in the complex relationship between care-givers, care-recipients and the families who need to believe that they are not abandoning their loved ones but rather entrusting them to those best equipped to deliver the care they need. Trust, then emerged as a necessity for managing the emotional experience of dependence and vulnerability.

\section{Lack of control}

Simulants commented on their experience of losing control when, for example, they were being pushed in a wheelchair:

I felt very vulnerable in a wheelchair. I had no control [F2].

This mention of control links vulnerability not just to the practical necessity of completing basic tasks but also the emotional importance of being able to act autonomously, a sub-theme which will be explored in more depth below. These accounts also demonstrate how the sense of vulnerability can potentially lead to other negative emotions including fear, anxiety and desperation

That's something that really builds up a whole vicious circle, and then the resident gets scared. And once they're scared their anxiety comes and confusion, fear. And once they're fearful they really don't want to do anything, and they're not willing to actually cooperate [F3].

This is one of several instances in which care-recipients found that the simulation helped them understand behaviour they might have previously dismissed as a resident being difficult or irrational. The data suggests new perspectives arising from the 
experience of lack of control that led to reflection on simulant's own care home practice.

\section{Theme 2 - Dignity in care}

Dignity is a core value in care and relates to the worth and value of persons as perceived by themselves and/or others. Again, epiphanies were evident in the data. The focus group data sub-themes which related to dignity are: discretion; autonomy; and identity.

\section{Discretion}

The simulation experience generated a deeper appreciation in simulants and student nurses of the need to be constantly aware of the dignity of those they care for and of what enables and diminishes it. At times the strategies employed were subtle and relied on care-giver discretion and again depended on an acute sensitivity to each care recipient's unique needs. This was illustrated most clearly in one care- recipient's account of an attempt to eat a slice of cheesecake with one hand:

I just kept picking up that whole entire thing where it was quite sticky and really gooey and it's cheesecake. I just want to plough in and I just couldn't get anything. And before l'd realised it, her [student] hand had just come across the table, she hadn't even looked at me, and she was just like that, and she just carried on talking. And just from that simple movement I was able to feed myself my cheesecake. And that was brilliant because there was no 'Oh do you want any help with that?' it was just a gentle little ... yeah, to make it blatant to everyone. It was just a little slide of a hand, place the fingers on it and just carried on talking [...] I didn't actually even notice that she'd done it until l'd actually finished [FG5].

Tellingly, the fact that the care-giver enables the recipient to achieve her goal of eating the cheesecake is a fairly minor aspect of the account. Far more valued were the discretion, sensitivity and lightness of touch with which the care-giver provides the assistance. The care-recipient is enabled to feed herself and although her dependence is subtly acknowledged, her dignity is maintained by providing the absolute minimal amount of support necessary. Both care-giver and care receiver seemed surprised at the impact of this small intervention. In the post-simulation focus group, both care-recipient and caregiver (student nurse) involved in the cheesecake situation were animated as they related their perspectives on this example culminating in giving each other a 'high five'.

\section{Autonomy}

The importance of being able to choose is a sub-theme running strongly through discussions of both vulnerability and dignity. The ability to make meaningful choices, both large and small, emerged as important in maintaining a sense of autonomy at a time when diminishing physical and mental abilities may restrict one's ability to express and validate selfhood. One participant vividly describes how important the ability to act on one's wishes is to maintaining this sense of self:

It made me realise that being powerless consumes one's humanity, that often you are left into pieces, shattered into pieces. That's the reason why you become lonely, you become sad, you tend to be withdrawn. Because although you want to do something, but you know you are physically restricted [FG3]. 
This powerful account associates loss of selfhood not primarily with physical vulnerability but with the inability to exercise autonomy, to exercise choices and thereby be able to act upon the world rather than merely be acted upon. In some instances a care-recipient's autonomy was compromised not merely by their physical impairments but because their care-giver had to make the difficult decision to deny their wishes on the basis of safety. In the following extract a care-giver weighs a care recipient's autonomy and privacy against his primary duty to keep her from harm:

l'll let you go to the bathroom, but you know if you look at the other ... the person you are giving care to there, you always worry about them. So you don't want anything to happen while they're in your care. So ... and then you want to give them their independence and their privacy but you've still got that security issue, so you're thinking ... like let me weigh the two, so security overweighs your privacy $(. .$.$) [FG3].$

Taking away a care-recipient's autonomy is clearly not something the care-giver does lightly. Indeed this may be an even more difficult decision to make if the carerecipient's experience has led them to appreciate that a resident's emotional needs are just as real as their physical needs and, though invisible, may even be subjectively experienced as equally important. In cases of severe impairment, when the care recipient can't express their emotional needs or act on them, participants reported that sometimes the only choice left is the choice to refuse cooperation. Appreciating this made a lot of the challenging behaviour they encountered working in care homes much easier to understand and empathise with:
Because I've worked in a specialised dementia unit so that dementia is very advanced. Most of them cannot verbalise, cannot find the right words. And mostly aggressiveness is seen during personal care when you have to do an intervention. And it could be that because of that person's disease ... but it could be because they have no other way of expressing it ... must be that the carers are thinking oh this resident's just so difficult to care for. But it could be that that's the person's way of expressing 'This is so embarrassing for me' [FG2].

The need to balance and prioritise concerns such as safety and comfort - both physical and psychological against giving residents meaningful choices emerged as both difficult and important. The care-giver's ability to make appropriate choices in balancing the need for safety with the desire for autonomy, and to make that choice understandable to the care recipient, depends greatly on the quality of the relationship between the two.

\section{Identity}

The concept of dignity also resonated strongly in the accounts of simulants who expressed newfound appreciation of how one's identity and value may be diminished as a result of a care experience. The need to experience self-worth assumed greater importance given the aforementioned dependence and vulnerability experienced by care-recipients. The most basic tenet of dignity seen as threatened was simply the sense of being treated like a human being rather than an inanimate object, as vividly captured in the following extract:

The first time I went outside yesterday and I was sat in the wheelchair there was so many people that were just looking at me, and it made me feel so uncomfortable. That must be how ... if someone does have a stroke and they are 
wheelchair bound they must feel so awful when people do just walk past them and just look at them. It did make me feel quite 'Oh my goodness, it's horrible' [FG2].

The third and final theme captures some of the core elements of 'good' or 'ethical care'. Whilst it can be argued that this encompasses an understanding of the experience of vulnerability and awareness of dignifying and undignifying elements of care, it goes further to explore the significance of communication, time and the fact that 'the little things make a difference'.

\section{Theme 3 - The organisation of care}

Good care is multi-faceted and, in the data from simulants and student nurses, related to the subtle and everyday organisational and relational features of care with subthemes of: communication; the little things make a difference; and time.

\section{Communication}

Communication between care-givers and care-recipients was presented as paramount, not just in terms of clearly communicating information and choices but also for finding appropriate ways to relate to care-recipients with different levels of impairment:

If they [care-givers] were standing here I might get intimidated because they are above my head. But because they're at my eye level it feels more comforting that way cos I can see them and I can ... and all this because I was partially blind - if they're up here I can't see them [FG1].

Communicating effectively with each care recipient also required a great awareness of the subtleties of communication, including body language and intonation. This was again enabled by a strong relationship with the care recipient, enabling care- givers to properly interpret both what care-recipients say and what they do not say:

I think you should be sensitive to cues - verbal and non-verbal cues because each one of us is unique and there's really no standard, no list of things to follow [FG4].

The little things make a difference

Care-recipients suggested that when being able to exercise smaller choices like what to eat and when to go to bed, became much more meaningful. Similarly, when caregivers were able to find ways to reduce the impact of physical impairments restricting autonomy, this was seen as hugely valuable, even if this was as simple as cleaning a spot from a care recipient's spectacles:

If you can't see very well it's very important that your glasses are very clean. So that was very important, she got the cloth and she asked where it was and have I got one, could she clean it, and to ensure that my hearing aids were in (...) little things, but they are very important in the resident's life [FG1].

Other examples that demonstrated consideration for the 'small' or 'minute' things are as follows:

You have to know which one prefers tea or coffee and who takes sugar, who 
doesn't take sugar - all these small things that can make a bit difference [FG6].

I think we have to consider holistic care from top to bottom. Treat everybody as an individual, think about the most basic things which we think is unimportant, but every little minute thing is important to the individual [FG1].

This newfound appreciation of the importance of little pleasures and small acts of thoughtfulness cannot be overemphasised. It is these that signal to residents that they are being responded to as persons, not just having their basic needs for safety, sustenance and hygiene met. Overall then, simulants valued being cared for by caregivers who know and appreciate them as unique, thinking and feeling individuals.

\section{Time}

Time was seen as important aspect of the organisation of care and in relation to caregivers' willingness and ability to be with residents, both for company and as a form of validation given by merely being present. Another important factor was carerecipients' ability to decide how to spend their time. Being afforded enough flexibility to make spontaneous choices rather than being constantly bound by routine and structure was another respect in which those in care could exercise their autonomy. Time was also experienced differently by simulants and care-givers:

The timescale is completely different. Like when I'm at work and say for instance I'm giving someone a bed bath, I know I'm going as quickly as I can. So to me it's going really quick, you know and obviously I'm doing the best job I can. But when I had my bed bath this morning, whole time just stopped still and it was just like "Oh my God the time scale is completely opposite ends of the scale, it's so different, it's unbelievable (...)" We had a lovely cup of tea this morning and it took no more than 5 minutes to get to but it felt like half an hour, forty minutes [FG5].

Participants also shared their experience of boredom:

An hour seems like two or three hours, specially when you're sat there...and it's hard to just sit there and do nothing [FG3].

One care recipient in particular summed up another aspect of the significance of time in care in this reflection on the simulation experience, again suggesting an epiphanous insight:

I feel like this simulation gave me a lot more time to actually look at the emotional needs of someone, rather than the physical. I think you can get really caught up in the physical 'Oh this patient might need to be turned' or you know 'are they clean?' Rather than I suppose how important I feel it is to always say 'Are you comfortable, is there anything else that I can do for you?' like 'How can I make you feel happier?' Like if you see someone that's isolated maybe think it's not just ... Some people just like their own space. And like respecting that people have the right to say 'I just want to spend some time on my own.' [FG3].

Among other things this statement neatly brings together the issues of dignity, communication and choice, and illustrates how something as simple as knowing when not to bother a care recipient is what best equates to good organisation of care. In general participants felt they had been well prepared to cater for residents' physical 
needs but it was the simulation experience that helped them fully appreciate that this was only part of the picture.

Overall elements identified in relation to the organisation of care suggested fundamental features of the art of care. Whilst care-givers' first responsibility remained the need to maintain the physical safety of care-recipients they now much better understood how the resident's wellbeing was affected by less tangible issues like feelings of vulnerability and autonomy as well as the need to preserve dignity in the face of increasing dependence. Moreover, the series of epiphanous insights shared by project participants indicated a newly-found awareness of the significance of small changes that they can make in the way they worked, and the huge difference these can make to the wellbeing of residents.

\section{Discussion}

The themes and sub-themes that emerged from the post-simulation focus group data resonate strongly with existing literature relating to ethics in care. Concepts such as autonomy, choice and respect for individual preferences are highly consistent with literature relating to principles of biomedical ethics (Beauchamp \& Childress, 2013) and also to literature on person-centred care (Dewing, 2002; McCormack, 2004; Edvardsson, Winbald \& Sandman, 2008; Nolan, Davies, Brown \& Keady, 2004). The Belgian sTimul model is underpinned by a particular approach to ethics in care - known as care ethics or ethics of care. There are various approaches to ethics of care (Edwards, 2009; Gilligan, 1982; Tronto, 1993), however, it is the 'foundational ethical framework' for 'dignity-enhancing nursing care' (Gastmans, 2013) that has most resonance with findings from the RIPE project post-simulation focus group findings.

Gastmans (2013) details three key concepts which relate to the elements of dignityenhancing care and to our data: vulnerability, care and dignity. His starting point is 'lived experience' which he relates to the process of care giving and care receiving and to dignity and vulnerability rather than 'abstract principles' such as autonomy:

Giving priority to concrete care experiences, which of course are those being shared not only by nurses but also by patients, relatives and other belonging to the care process, reveal that the phenomenon of nursing care and the ethical problems associated with it are far more complicated than can be captured by a mere theoretical approach [...] nursing ethics can benefit from a better understanding of care experiences as a whole and the rich and complex context within which they are situated. (Gastmans 2013, p.144)

The post-simulation focus group data confirm that there is much to be gained from prioritising concrete care experiences. This is not just for 'nurses' and 'patients' but for all care-givers and care-recipients.

Gastmans (2013, p. 146) refers to 'vulnerability' as a 'profound lived experience', as 'an essential part of the human condition' and as relating to the risk of harm. He distinguishes between 'ordinary' and 'extraordinary' vulnerability and points to the experience of dementia as representing extraordinary vulnerability. Gastmans (2013, p. 146) argues that 'the essence of care' can be summarised as 'responding to vulnerability'. Other authors suggest that vulnerability is best understood as 'a matter of degree that varies with the social, cultural or economic context the individual finds her/himself in' (Ganguli-Mitra \& Biller-Andorno, 2011, p. 240). Kipnis (2004) suggests 
six categories of vulnerability: cognitive and communicative vulnerability; institutional vulnerability; deferential vulnerability; medical vulnerability; economic vulnerability; and social vulnerability.

The post-simulation focus group data confirm the significant relationship amongst vulnerability, care-giving and care-receiving. Care-recipients (simulants) seemed surprised that their experience of receiving care resulted in their feeling vulnerable. Findings relating to dignity in care also resonate with Gastmans' claim that this represents a 'normative standard' and leads to the question 'what does good care mean?' He answers: 'This is the care that, given the vulnerable status of the patient, supports the dignity of the human person as much as possible' (Gastmans, 2013, p. 148). Hence the claim that 'dignity-enhancing care' is what is aspired to. The realisation of the impact of dependency and fear of abandonment and potential loss of dignity resulted in what we would refer to as 'care epiphanies' as experienced by the simulation participants. The 'organisation of care' theme highlights additional features of good or ethical care that enable dignity to be maintained and vulnerability to be acknowledged and responded to ethically. The sub-theme of communication resonates strongly with Gastmans' discussion of care as 'a dialogical interpretative process' whereby:

It is the situation of vulnerability of the fellow human being that prompts us to care for the other. In this way, care starts from the appeal to be susceptible to the lot of other people in an attentive, responsible, competent and responsive way (Gastmans, 2003, p. 147).

Recent discussions of the significance of the 'slow movement' for ethics and care (Gallagher, 2012, 2013; Lohne et al., 2016) reinforce the relevance and multi-faceted implications of time in care. The care-givers' and care-recipients' experience of time during the simulation experience offered other epiphanous events to reflect on - the disparity between imagined and actual response times, the perceived slowness of time when inactive and the perceived pressure to fill time with activities.

So although there is much in the focus group data that resonates with previous ethics scholarship and research, what is new is the realisation that the immersive simulation experience resulted in participants' experience of, and ability to articulate, epiphanies relating to everyday care practices. As suggested earlier, the definition of 'epiphany' is 'a moment when you suddenly feel that you understand, or suddenly become conscious of, something that is very important to you' (Cambridge English Dictionary, undated). The concept has assumed a central role in Christianity, literature and philosophy and literary scholars have discussed the idea of 'epiphany' in relation to the work of James Joyce. Narula (undated) discusses the essays in Dubliners and defines 'epiphanies' as 'the idea that each character arrives at some sort of life-changing revelation at the end of each short story'.

Descriptions of revelations, insights or 'aha' moments characterise well the discoveries made by simulation care-recipients. Whilst there may not be a 'transformation' that is 'spiritual', as suggested by Joyce, there were undoubtedly many experiences that led participants to describe a diverse range of epiphanies relating most particularly to: the experience of vulnerability; dignity in care; and the organisation of care. We are supportive of the idea that, whilst a care-recipient cannot be described as a 'man of letters', she/he can and should 'record these epiphanies with extreme care, seeing that they are the most delicate and evanescent of moments'. Making time and space to reflect on and articulate these care epiphanies appear to be of crucial importance for 
ethics education. The finding that this immersive simulation experience, in particular, is epiphanous is supported by findings from the first qualitative study on the sTimul experience (Vanlaere et al., 2012, p. 75) with participants referring to their experiences as 'eye-openers' and 'new insights'. Vanlaere et al. (2012, p. 75) had noted that: 'It is particularly the experience of physical and mental misery that made many participants stop and think'. In our data, happy experiences of good and dignifying care - as in the cheesecake example - also afforded new insights, to what we would refer to as care epiphanies.

\section{Conclusion}

The focus group data suggest that participants' experienced care epiphanies following the immersive simulation. Participants' reported that the experience had changed their perspectives on caregiving and, most particularly, on the experience of care-recipients. Gaining insights as to what it feels like to be dependent and vulnerable and to fear abandonment, loss of control and boredom clearly had a powerful and profound immediate impact on the simulants.

Initial reports from the participants, then, suggest that the simulation experience did indeed provide a range of epiphanous events with the potential to impact positively on care practice. At this stage we cannot know whether the impact of these initial responses will translate into care-changing practices over the longer term.

Quantitative data collected in the project will provide an indication of the sustainability of the impact of the simulation experience gauging the impact of the three ethics interventions (face to face ethics teaching; reflective groups and immersive simulation) on moral sensitivity, moral stress, ethical leadership and empathy. This will be reported on the completion of the RIPE project towards the end of 2016 What can be claimed, on the basis of the qualitative data presented here, is that the simulation experience prompted reflection on three ways or modes of thinking described by Dieckmann et al ((2007): the physical in terms of the significance of the environment and equipment in relation to simulants sense of control, privacy or abandonment; the semantical in relation to the way they referred back to concepts that were part of the introduction to good care (vulnerability and dignity, for example); and the phenomenal evidenced most acutely in the descriptions of epiphanous experiences.

Findings from the simulation experience and from the RIPE project overall urge reflection on the meaning and outcomes of 'ethics education' (Gallagher, 2016). Most particularly, as the RIPE project findings emerge, the research team will revisit perspectives on ethical competence (Gallagher, 2006; Kulju, Stolt, Suhonen \& LeinoKilpi, 2015; Pohling, Bzdok, Eigenstetter, Stumpt \& Strobel, 2015) for care and keep the question 'what counts as success in ethics education for care-givers?' under review. We recommend further qualitative research to gather data relating to recipients of ethics education in different countries and, most particularly, to invite them to reflect on, articulate, record and learn from these 'most delicate and evanescent of moments'.

\section{ACKNOWLEDGEMENTS}


The RIPE project would not have been possible without support and funding from the Ethox Foundation and the generous and courageous participation of research participants. Thank you. We thank also care home managers who supported care-givers' participation, student nurses who provided care, colleagues in the School of Health Sciences, members of the Advisory Group and sTimul colleagues who gave their time and shared their expertise to ensure the interventions ran smoothly. Finally, we owe a debt of gratitude to Christopher Herbert and Sophie-Grace Chappell for sharing perspectives on the concept of epiphany contributing to the development of the article.

\section{REFERENCES}

BBC. (2011). Epiphany. Retrieved from http://www.bbc.co.uk/religion/religions/christianity/holydays/epiphany.shtml

BBC. (2014). Care home abuse: staff sacked or suspended over poor care. Retrieved from http://www.bbc.co.uk/news/uk-27217218.

BBC. (2015). Purpeck Care Home: Report highlights abuse and neglect. Retrieved from http://www.bbc.co.uk/news/uk-england-dorset-31417084

Beauchamp, T., \& Childress, J. (2013). Principles of Biomedical Ethics $\left(7^{\text {th }}\right.$ Ed.). Oxford, UK: Oxford University Press.

Braun, V., \& Clarke, V. (2006). Using Thematic Analysis in psychology. Qualitative Research in Psychology, 3(2), 77-101.

Carroll, J., \& Messenger, J. (2008). Medical Simulation: The new tool for training and skill assessment. Perspectives in Biology and Medicine, 51(1), 47-60.

Chappell, S-G. (undated). OU people profiles - Professor Sophie-Grace Chappell. Retrieved .,from http://www.open.ac.uk/people/tc2973

Copley, A. J. (2001). Creativity in Education and Learning: A Guide for Teachers and Educators. Abingdon, UK: Routledge.

Dewing, J. (2002). From ritual to relationship: A person-centred approach to consent in qualitative research with older people who have dementia. Dementia, 1(2), 157- 171.

Drieckmann. P., Gaba, D. \& Rall, M. (2007) Deepening the Theoretical Foundations of Patient Simulation as Social Practice. Simulation in Healthcare 2(3), 183-193

Edvardsson, D., Winblad, B., \& Sandman, P.O. (2008). Person-centred care of people with severe Alzheimer's disease: Current status and ways forward. The Lancet Neurology, 7(4), 362-367.

Edwards, S. (2009). Three versions of an ethics of care. Nursing Philosophy, 10, 230240.

Francis, R. (2013). The Mid Staffordshire NHS Foundation Trust Public Inquiry Final 
Report. Retrieved from

http://webarchive.nationalarchives.gov.uk/20150407084003/http://www.midstaffspubl icinquiry.com

Gallagher, A. (2006). The teaching of Nursing Ethics: content and method. Promoting ethical competence. In A. Davis, V. Tschudin \& L. de Raeve (Eds.), The Essentials of Teaching and Learning Nursing Ethics: Perspectives and Methods (pp. 223239). London, UK: Churchill Livingstone Elsevier.

Gallagher, A. (2012). Editorial: Slow ethics for nursing practice. Nursing Ethics, 19(6), 711-713.

Gallagher, A. (2013). Slow ethics: A sustainable approach to ethical health care practice? Clinical Ethics, 8(4): 98-104.

Gallagher, A., \& Cox, A. (2015). Researching Interventions to Promote Ethics in social care. Working Papers in the Health Sciences, Spring. Retrieved from http://www.southampton.ac.uk/assets/centresresearch/documents/wphs/AGRIPE.pdf

Gallagher, A. (2016). Editorial: What counts as ethics education? Nursing Ethics, 23(2), 131.

Ganguli-Mitra, A., \& Biller-Andorno, N. (2011). Vulnerability in healthcare and research ethics. In R. Chadwick, H. ten Have \& E. M. Meslin (Eds.), The Sage Handbook of Health Care Ethics: Core and Emerging Issues (pp. 239-250). Los Angeles, CA: Sage.

Gastmans, C. (2013). Dignity-enhancing nursing care: A foundational ethical framework. Nursing Ethics, 20(2), 142-9.

Gilligan, C. (1982). In a Different Voice: Psychological Theory and Women's Development. Cambridge, MA: Harvard University Press.

Help the Aged. (2007). My Home Life: Quality of life in care homes - A review of the literature. London, UK: Help the Aged.

Joyce, J. (1992). Dubliners. London, UK: Penguin Books.

Kipnis, K. (2004). Vulnerability in Research Subjects: A Bioethical Taxonomy. National Bioethics Advisory Committee, Bathesda. Retrieved from http://www.aapcho.org/wp/wp-content/uploads/2012/02/KipnisVulnerabilityinResearchSubjects.pdf

Kulju, K., Stolt, M., Suhonen, R., \& Leino-Kilpi, H. (2015). Ethical competence: A concept analysis. Nursing Ethics, 23(4), 401-412.

Lohne, V., Hoy, B., Lillesto, B., Saeteren, B., Heggestad, A. K., Aasgaard, T., Caspari, S., Rehnsfeldt, A., Raholm, M. B., Lindwall, L., \& Naden, D. (2016). Fostering dignity in the care of nursing home residents through slow caring. Nursing Ethics.

Retrieved from

http://nej.sagepub.com/content/early/2016/02/04/0969733015627297.abstract

Levett-Jones T. \& Lapkin S. (2014) A systematic review of the effectiveness of simulation debriefing in health professional education. Nurse Education Today 34, pp.358-363 
MacFarlane, J. (2013, January 5). Scandal of neglect in Britain's care homes: NHS survey of 63,000 elderly residents reveals one in three are living in fear of abuse Mail Online $5^{\text {th }}$ January Retrieved from http://www.dailymail.co.uk/news/article2257703/Scandal-neglect-Britains-care-homes-NHS-survey-63-000-elderlyresidents-reveals-living-fear-abuse.html

McCormack, B. (2004). Person-centredness in gerontological nursing: An overview of the literature. Journal of Clinical Nursing, 13, Supplement s1: 31-38.

McFarlane, L., \& McLean, J. (2003). Education and training for direct care workers. Social Work and Education: The International Journal, 22(4), 385-399.

Narula, N. (undated). The Epiphany as the evanescent moment: Flashes of unintellectual light in James Joyce's Dubliners. Arts and Sciences Writing Programme. Retrieved from http://www.bu.edu/writingprogram/journal/pastissues/issue-5/narula/narula-writer/

Nolan, M. R., Davies, S., Brown, J., \& Keady, J. (2004). Beyond 'person-centred' care: A new vision for gerontological nursing. Journal of Clinical Nursing, 13, 45-53.

Northern Ireland Human Rights Commission. (2012). In Defence of Dignity: The Human Rights of Older People in Nursing Homes. Northern Ireland Human Rights Commission, Belfast

Office for National Statistics. (2014). Changes in the Older Resident Care Home Population between 2001 and 2011. Retrieved from https://www.ons.gov.uk/peoplepopulationandcommunity/birthsdeathsandmarriages/a geing/articles/changesintheolderresidentcarehomepopulationbetween2001and2011/ 2014-08-01

Pohling, R., Bzdok, D., Eigenstetter, M., Stumpf, S., \& Strobel, A. (2015). What is Ethical Competence? The Role of Empathy, Personal Values, and the Five-Factor Model of Personality in Ethical Decision-Making. Journal of Business Ethics, Retrieved from http://link.springer.com/article/10.1007/s10551-015-2569-5

Preshaw, D., Brazil K., \& McLaughlin, D. (2016). Ethical issues experienced by healthcare workers in nursing homes: Literature review. Nursing Ethics, 23(5), 490506.

Sawer, P. (2014, December 14). Care Home Scandal: My father suffered hellish treatment. The Telegraph. Retrieved from

http://www.telegraph.co.uk/news/health/news/11292321/Care-home-scandal-Myfather-suffered-hellish-treatment.html

Skills for Care. (2013). The size and structure of the adult social care sector and workforce in England, 2013. Retrieved from http://www.skillsforcare.org.uk/Document-library/NMDS-SC,-workforce-intelligenceand-innovation/Research/Size-and-structure-2013-vweb2.pdf

Skills for Care. (2016). Care certificate. Retrieved from http://www.skillsforcare.org.uk/Learning-development/Care-Certificate/CareCertificate.aspx

Suhonen, R., Stolt, M., Launis, V., \& Leino-Kilpi, H. (2010). Research on ethics in nursing care for older people: A literature review. Nursing Ethics, 17(3), 337-52. 
Trobec, I., \& Starcic, A. I. (2015). Developing nursing ethical competences online versus in the traditional classroom. Nursing Ethics, 22(3), 352-366.

Tronto, J. (1993). Moral Boundaries: A Political Argument for an Ethics of Care. New York: Routledge.

Vanlaere, L., Coucke, T., \& Gastmans, C. (2010). Experiential learning of empathy in a care-ethics lab. Nursing Ethics, 17(3), 325-336.

Vanlaere, L., Timmermann, M., Stevens, M., \& Gastmans, C. (2012). 'An explorative study of experiences of healthcare providers posing as simulated care receivers in a 'care-ethical' lab.' Nursing Ethics, 19(1), 68-79.

Williams, V., Kinnear, D., \& Victor, C. (2016). 'It's the little things that count': healthcare professionals' views on delivering dignified care: A qualitative study. Journal of Advanced Nursing, 72(4), 782-790.

Willis, J. (2007). The neuroscience of joyful education. Retrieved from

http://www.district287.org/uploaded/A_Better_Way/ME_PrereadingJudyWillisEdLeadArt .pdf 


\section{APPENDIX 1}

Figure 1 - SUPPORTING MATERIAL 1

Overview of the simulation intervention

(adapted from sTimul publication)

\begin{tabular}{|c|c|}
\hline Day 1 & Day 2 \\
\hline $\begin{array}{l}\text { Arrive 12md Saturday } \\
\text { Lunch } \\
\text { Briefing of simulants and time to amend } \\
\text { profile if desired } \\
\text { Briefing of students } \\
\text { Handover of profiles from simulants to } \\
\text { student nurses and questions }\end{array}$ & $\begin{array}{c}\text { From 6am Sunday } \\
\text { Simulation experience }\end{array}$ \\
\hline $\begin{array}{c}\text { 2pm to } 7 \mathrm{pm} \\
\text { Simulation experience }\end{array}$ & $\begin{array}{l}1 \mathrm{pm} \\
\text { End of simulation, lunch and debriefing }\end{array}$ \\
\hline $\begin{array}{l}\text { 7pm to 8pm } \\
\text { Initial reflection with simulants (30 } \\
\text { minutes) \& break (30 minutes) } \\
\text { Break and initial reflection with students } \\
\text { Feedback of key points to each group }\end{array}$ & $\begin{array}{l}\text { 2pm to 3pm } \\
\text { Individual feedback from simulants to } \\
\text { students [How did it feel to receive care?] } \\
\text { and individual feedback from students to } \\
\text { simulants [How did it feel to deliver } \\
\text { care?] }\end{array}$ \\
\hline $\begin{array}{c}\text { 8pm to } 12 \mathrm{mn} \\
\text { Simulation experience } \\
\text { [Care is not delivered overnight] }\end{array}$ & $\begin{array}{l}\text { 3 to } 4 \mathrm{pm} \\
\text { Post-simulation focus group }\end{array}$ \\
\hline
\end{tabular}




\section{APPENDIX 2}

Figure 2 - SUPPORTING MATERIAL 2

Profile to be chosen by the simulant/care recipient

(adapted from sTimul publication)

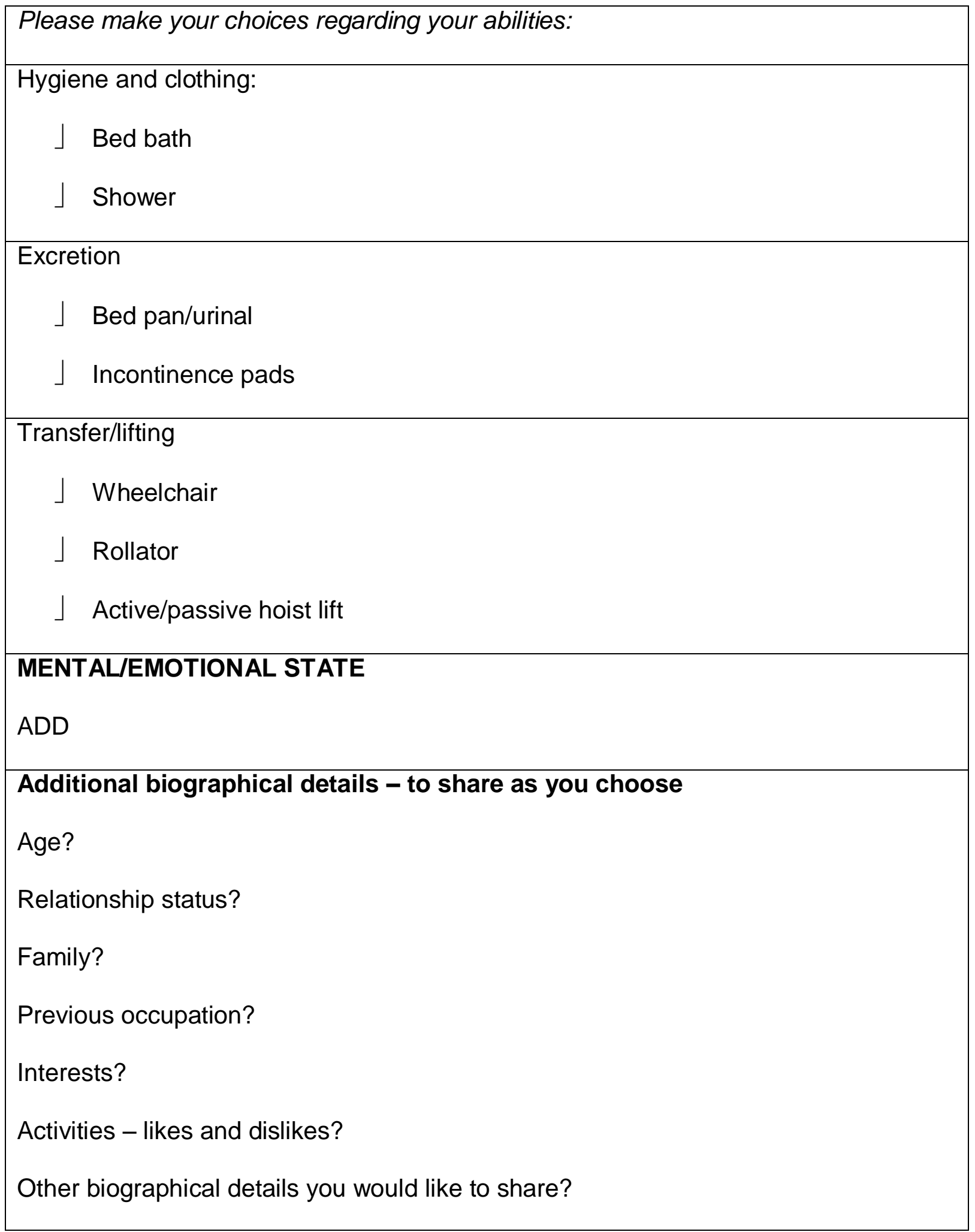

